\title{
Elementos do saber profissional do professor que ensina matemática: o Compêndio de Pedagogia de Antônio Marciano da Silva Pontes
}

\author{
Elements of the professional knowledge of the teacher who teaches \\ mathematics: the Compendium of Pedagogy of Antônio Marciano da \\ Silva Pontes
}

\author{
Viviane Barros Maciel $^{1}$ \\ Wagner Rodrigues Valente ${ }^{2}$
}

\section{Resumo}

Este texto analisa em perspectiva histórica elementos do saber profissional do professor que ensina matemática no Compêndio de Pedagogia de Antônio Marciano da Silva Pontes (1873). Traz resultados parciais obtidos pelo desenvolvimento de projeto de pesquisa de doutorado integrante de projeto temático amplo de pesquisa. O objetivo do projeto temático é caracterizar o saber profissional do professor que ensina matemática nos primeiros anos escolares no período de 1890 a 1990. A pesquisa de doutorado intenta caracterizá-lo por meio dos manuais pedagógicos. O texto mobiliza categorias vindas de estudos sócio-históricos da educação como saberes para ensinar e saberes a ensinar desenvolvidos por autores da Equipe de Pesquisa em História das Ciências da Educação (ERHISE) da Universidade de Genebra, na Suíça. Tal aporte teórico-metodológico coloca o saber no centro dos estudos sobre formação de professores. Em específico, toma como material empírico para a análise o Compêndio de Pedagogia de Antônio Marciano da Silva Pontes, escrito em 1873, para a formação de professores nas escolas normais do Rio de Janeiro e de São Paulo. Como resultados do estudo, tem-se a caracterização dos primeiros elementos sistematizados e organizados como uma matemática para ensinar elaborada para constituir-se numa ferramenta de trabalho do futuro professor da escola primária.

Palavras chave: pedagogia; formação de professores; história da educação matemática.

\section{Abstract}

This text analyzes in historical perspective the elements of professional knowledge of the teacher who teaches mathematics in the Compendium of Pedagogy of Antônio Marciano da Silva Pontes (1873). It brings partial results obtained by the development of a doctoral research project integral to a broad thematic research. The project integral aims to characterize the professional knowledge of the teacher who teaches mathematics in the primary school in the period from 1890 to 1990. The doctoral research tries to characterize it through the pedagogical textbooks. The text mobilizes categories of socio-historical studies of education, such as knowledge to teach and knowledge for teaching developed by authors of the Research Team on History of Educational Sciences (ERHISE) of the University of Geneva, Switzerland. This theoretical-methodological contribution places knowledge at

\footnotetext{
${ }^{1}$ Universidade Federal de Goiás/Regional Jataí | barrosmaciel@gmail.com

${ }^{2}$ Universidade Federal de São Paulo | ghemat.contato@gmail.com
} 
the center of studies on teacher education. Specifically, it takes as an empirical material for the analysis the Compendium of Pedagogy of Antônio Marciano da Silva Pontes, written in 1873, for the training of teachers in the normal schools of Rio de Janeiro and São Paulo. As results of the study, we have the characterization of the first elements systematized and organized as a mathematics for teaching elaborated to constitute a working tool of the future teacher of the primary school.

Keywords: pedagogy; teacher training; history of mathematics education.

\section{Considerações iniciais}

Este texto tem por objetivo contribuir com o desenvolvimento de projeto temático de pesquisa amplo ${ }^{3}$, cujo objetivo é caracterizar o saber profissional do professor que ensina matemática. Neste caso, a investigação volta-se, especificamente, para a docência nos primeiros anos escolares. Como caracterizar o saber profissional para o exercício da docência em matemática nesse nível escolar? A resposta a tal questão vem sendo elaborada por meio do desenvolvimento de vários subprojetos de pesquisa que integram organicamente o projeto temático, tendo em conta monografias de iniciação científica, mestrados, doutorados e pós-doutorados. De modo particular, este texto é originário de desenvolvimento de projeto de doutorado ${ }^{4}$, apresentando resultados parciais dessa pesquisa.

A perspectiva teórico-metodológica adotada pelo projeto temático, orientadora de todos os subprojetos, considera a análise histórica. Assim, na investigação do saber profissional do professor que ensina matemática tem-se por premissa que tal saber vem sendo construído historicamente. Desse modo, caberá aos pesquisadores a elaboração teórica desse saber, tornando-o inteligível, a partir de vestígios e rastros deixados no presente, da atuação profissional dos professores.

Neste presente estudo, com o intuito de caracterizar elementos do saber profissional do professor que ensina matemática, analisou-se um manual de Pedagogia - um dos primeiros a circular no Brasil - utilizado na formação de professores. Trata-se da obra de Antônio Marciano da Silva Pontes, que teve sua primeira edição em $1873^{5}$.

Assim, tendo em vista a realização de estudo histórico e a escolha desse material empírico como fonte de pesquisa, este texto, mais precisamente, intenta responder à seguinte questão: Que elementos podem ser considerados integrantes do saber profissional do professor que ensina matemática nos primeiros anos escolares contidos no "Compêndio

\footnotetext{
${ }^{3}$ O projeto conta com o financiamento da FAPESP, na modalidade "projeto temático", pesquisa para ser desenvolvida no período 2017-2022. Tem como equipe responsável Wagner Rodrigues Valente (coordenador) e os pesquisadores associados: Luciane de Fátima Bertini, Neuza Bertoni Pinto e Rosilda dos Santos Morais.

Maiores informações sobre o projeto podem ser lidas no endereço:

http://www.bv.fapesp.br/pt/auxilios/98879/a-matematica-na-formacao-de-professores-e-no-ensino-processose-dinamicas-de-producao-de-um-saber-p/

${ }^{4}$ Projeto de doutorado de Viviane Barros Maciel, já em seu terceiro ano de desenvolvimento, com Exame de Qualificação realizado em abril de 2018. A pesquisa incluiu estágio de doutorado sanduíche na Universidade de Limoges, França, tendo auxílio da CAPES-COFECUB, no ano de 2017.

${ }^{5}$ Trevisan (2011) analisa o manual de Pontes publicado em 1873, na Typ. da Reforma, Rio de Janeiro. No texto será tomada como referência a terceira edição da obra, publicada em 1881. A obra pertence ao acervo da Biblioteca da Faculdade de Educação da USP e pode ser consultada, por meio de solicitação, em formato digital.
} 
de Pedagogia : para uso dos alumnos da Escola Normal da Província do Rio de Janeiro", de Antônio Marciano da Silva Pontes?

\section{O saber profissional do professor}

As pesquisas sobre o saber profissional do professor têm sido tema de estudos de muitas investigações, nelas é possível encontrar vários modos de caracterizar esse saber. Neste texto, alinhado às perspectivas postas no projeto temático, trataremos o saber profissional do professor considerando os saberes de formação dado pela articulação entre os saberes a ensinar e os saberes para ensinar (HOFSTETTER; SCHNEUWLY, 2009). Há que se destacar que tais saberes são tratados de modo distinto daquele abordado por estudos que consideram o ponto de vista da prática, estudos que analisam a mobilização dos saberes do professor no fazer, na ação pedagógica, conforme Valente (2018). Diferentemente dessa perspectiva de considerar o saber profissional visto na prática pedagógica, considera-se o saber profissional vindo dos saberes de formação dos professores. Desse modo, tem-se os saberes a ensinar como saberes originariamente produzidos pelas disciplinas universitárias, pelos diferentes campos científicos considerados importantes para a formação dos professores; e, de outra parte, os saberes para ensinar, que são tratados como uma especificidade da docência, ligam-se àqueles saberes próprios para o exercício da profissão docente. Assim, ambos os saberes se constituem como saberes da formação de professores, mas a expertise profissional, o que caracteriza a profissão de professor é a posse dos saberes para ensinar. No entanto, cabe enfatizar, como bem destaca o projeto temático: esses saberes estão em articulação com os saberes a ensinar.

A investigação em curso, como se disse, integra um projeto temático, constituindo-se no desenvolvimento de tese de doutorado, e pauta-se pela análise do saber profissional em perspectiva que não leva em conta os saberes mobilizados pelos professores na prática pedagógica. $O$ interesse investigativo volta-se para a análise dos processos e dinâmicas de constituição do saber profissional do professor que ensina matemática, considerando os saberes formalizados - os saberes objetivados. Analisa-se, dessa maneira, o percurso histórico que elabora saberes objetivados. Localizando-se no campo dos saberes objetivados, a pesquisa tem em vista:

(...) a mesma zona semântica da cultura, das regras, dos valores. Esta zona refere-se provavelmente a realidades que têm $\mathrm{o}$ estatuto de representações ou de sistemas de representações dando lugar a enunciados proposicionais e tendo por objeto uma valorização social sancionada por uma atividade de transmissão-comunicação. Essas realidades distinguem-se daqueles que as enunciam ou daqueles que delas se apropriam. Elas são conserváveis, cumulativas e apropriáveis. No âmbito dessa zona semântica, os saberes objetivados podem ser definidos como enunciados de proposições sendo objeto de um julgamento social que se situa no registro da verdade ou da eficiência. Eles podem mesmo ser considerados duplamente como enunciados: de uma parte eles formalizam uma representação do real (eles dizem 'alguma coisa' sobre o real), de outra parte eles enunciam uma correspondência, uma ligação entre essa representação e o objeto representado (a noção de verdade é 
a afirmação de uma correspondência) (BARBIER, 2014, p. 9 tradução nossa).

O estudo do saber profissional do professor, portanto, busca elaborar um saber objetivado em termos de saberes a ensinar e saberes para ensinar. Em específico, ao tratar da docência em matemática, tem como hipótese teórica de trabalho a admissão de uma matemática a ensinar e de uma matemática para ensinar. Considera-se, assim, a existência de dois regimes para a matemática, admitindo-se a sua presença na formação de professores e no ensino: a matemática a ensinar, originária do campo disciplinar matemático, tida como um objeto de ensino; e a matemática para ensinar, fruto de reelaboração ao longo do tempo, pelo ofício da docência, de saberes para ensinar matemática, objetivando em cada época histórica, uma ferramenta para ensinar matemática.

A partir dessa síntese do aparato teórico-metodológico, e da escolha já anteriormente anunciada, de estudo de um manual de pedagogia, é possível explicitar que o estudo do saber profissional do professor que ensina matemática - da expertise própria do profissional da docência - refere-se à pesquisa da matemática para ensinar. Assim, tratar dos elementos integrantes deste saber profissional, prescritos no manual de Pontes, aos quais se busca neste texto, leva-nos a investigar a matemática para ensinar. Tal perspectiva permite reelaborar a questão norteadora do texto expressando-a de modo mais refinado como: Que matemática para ensinar está objetivada no "Compêndio de Pedagogia: para uso dos alumnos da Escola Normal da Província do Rio de Janeiro", de Antônio Marciano da Silva Pontes?

\section{Manuais de pedagogia e os saberes profissionais da docência}

Um dos primeiros estudos de maior extensão sobre a formação matemática dada aos futuros professores, alunos da Escola Normal de São Paulo ${ }^{6}$, foi realizado por Valente (2011). Nele, o autor abordou o período 1875 a 1930, investigando, sobretudo por meio de livros didáticos, que matemática esteve presente na formação dos professorandos daquela Escola. Na obra, o autor concentra sua atenção nas rubricas matemáticas indicadas nos programas de formação dos professores, em particular na aritmética e na geometria. Fiando-se em pesquisas realizadas sobre a formação de professores, no âmbito da história da educação, o autor não considerou, em seu corpus empírico para a pesquisa, os manuais de pedagogia. Na obra, o autor justificou a sua opção ao mencionar que a literatura sobre o assunto indicava que, mesmo tendo em conta a existência da disciplina "Methodica e Pedagogia", de acordo com o Regulamento de 1874, da Escola Normal de São Paulo, tal rubrica não era ministrada com o objetivo de formação profissional do professor; ela voltava-se, preferencialmente, para a formação de dirigentes do ensino público (KULESZA, 1998; MONARCHA, 1999 apud VALENTE, 2011).

\footnotetext{
${ }^{6}$ Ícone da formação de professores para os primeiros anos escolares, da Monarquia à República, a Escola mudou várias vezes a sua estrutura recebendo variadas denominações tais como: Escola Normal, Escola Normal de São Paulo, Escola Normal da Capital, Escola Normal Secundária, Escola Normal Primária, Instituto Pedagógico, Instituto de Educação e Escola Caetano de Campos, dentre outros nomes oficiais.
} 
Com o avanço das pesquisas sobre a formação matemática do professor dos primeiros anos escolares em perspectiva histórica ${ }^{7}$, e o recente desenvolvimento do projeto temático interessado no saber profissional do professor que ensina matemática, mencionado anteriormente; e, ainda, tendo em vista a investigação em curso - de elementos do saber profissional em manuais pedagógicos indicados para a formação de professores no curso primário - como um de seus subprojetos, houve necessidade de ampliar o material empírico a ser analisado, reunindo-se aos manuais pedagógicos de matemática, os manuais $^{8}$ de pedagogia, uma vez que, tais materiais revelaram-se como depositários de saberes objetivados para a formação de professores.

Internacionalmente, os manuais de pedagogia foram exaustivamente estudados por Michèle Roullet (2001). A autora mostrou que a emergência das ciências da educação alimentou o debate sobre a formação profissional dos professores. E, em termos dos manuais de pedagogia, eles se mostraram como "um instrumento de 'profissionalização' " (ROULLET, 2001, p. 37).

Tendo também por referência Roullet (2001), Trevisan (2011) elaborou uma história dos manuais de pedagogia, em sua tese de doutoramento. Nela a autora destaca que

os manuais de Pedagogia que circularam no século XIX se constituem em importantes fontes de estudo e de ensino de Pedagogia, pois eram eles que apresentavam aos futuros professores o que era necessário saber, conhecer, fazer para ser um bom professor e inclusive quais eram as virtudes e hábitos necessários para ser professor (TREVISAN, 2011, p.204).

Os manuais pedagógicos, segundo a autora, "ensinam a ensinar ou contém os saberes necessários, e, por vezes, as práticas também, de uma determinada disciplina para a formação do professor", práticas estas que são sintetizadas e divulgadas nos manuais (TREVISAN, 2011, p.44). Pois segundo a autora, tanto os autores de manuais quanto os manuais propriamente ditos,

tiveram papel relevante ao divulgar as práticas ou as novas práticas que foram se estabelecendo nesse segundo momento, ao sintetizar e divulgar as novas bases da Pedagogia, os métodos de ensino, as traduções que fizeram de manuais teóricos escritos por autores estrangeiros, os conteúdos tidos como necessários e importantes para os futuros professores (TREVISAN, 2011, p.187).

Tudo isto eleva os manuais de pedagogia como vetores, meios de produção e divulgação de saberes e práticas. Outro exemplo desta assertiva se encontra na tese de Villela (2002) que investiga, mediante perspectiva histórica, a formação realizada nas escolas normais do século XIX. Segundo a autora, com o surgimento da escola normal do Rio de Janeiro, a formação de professor passa do tipo "artesanal" para "profissional". A distinção entre novos "professores" e antigos "mestres", se daria, especialmente, pelo domínio de

\footnotetext{
${ }^{7}$ Citem-se os estudos recentemente realizados por Silva (2017), Guimarães (2017), Pinheiro (2017) e Oliveira (2017).

${ }^{8}$ Adotamos aqui, os modos de tratar as obras didáticas utilizados por Oliveira, et al. (2017, p. 57) segundo os quais, os termos manuais e compêndios designavam obras para o ensino que serviriam de guia ao professor, enquanto livros de leitura ou livros didáticos eram indicados para o uso do aluno.
} 
conteúdos e métodos e aquisição de uma postura, que Villela denomina ethos profissional. Assim, com este lugar especializado de formação de professor, o que se improvisava como método e conteúdo, agora se normatizava constituindo, desse modo, saberes da profissão (VILLELA, 2002, p.115). E os manuais de pedagogia, nesta ordem, representavam um dos instrumentos de profissionalização do professor, que traziam em suas páginas saberes objetivados para ensinar.

Gilles Ubrich (2014) ao investigar as apropriações do método intuitivo de Ferdinand Buisson por alunos da escola normal na França, investigando manuais de pedagogia entre outros tipos de obras utilizadas por alunos em formação, afirma serem estes "prolongamentos e aprofundamentos dos conteúdos transmitidos pelos formadores" (UBRICH, 2014, p.205) defende os manuais como instrumento de profissionalização. Segundo o autor, estes se constituem em obras que poderão ser tomadas como:

Guia por excelência dos futuros professores que irão assegurar e assumir a delicada relação que eles mantêm com seus alunos, e sem dúvida como espelhos das lições dadas nas escolas normais, uma vez que seus autores são, geralmente, diretores das escolas normais, inspetores primários, inspetores de curso superior, ou inspetores gerais, todos ligados a diversos graus, nas ações de formação ou, pelo menos, exercendo responsabilidades no desenvolvimento e o desenvolvimento do sistema em vigor (UBRICH, 2011, p. 269, tradução nossa).

Seja como for, nota-se a importância de estudo dos manuais de pedagogia como vetores da profissionalização da docência, textos que buscam sistematizar o saber pedagógico, por meio das orientações dadas aos professores. Desse modo, ganha relevância a análise de tais manuais, em particular, o de Silva Pontes, pelo seu pioneirismo na sistematização dos saberes profissionais da docência, com uso nas escolas normais do Rio de Janeiro e de São Paulo.

\section{O Compêndio de Pedagogia de Silva Pontes}

Na primeira leitura do Compêndio de Pedagogia de Antônio Marciano da Silva Pontes, pela capa da obra, tem-se as seguintes informações: o autor foi professor vitalício da primeira cadeira da Escola Normal do Rio de Janeiro e diretor da Escola Normal da Província do Rio de Janeiro.

Segundo as palavras de Abílio Borges ${ }^{9}$, que apresentou sua obra, tratava-se de um compêndio que trazia, muito bem combinado, o arranjo de todas as matérias de modo conciso e claro, em um pouco mais de 200 páginas. Em palavras simples, Borges também caracterizou o que entendia ser um predicado das obras para a docência, aquelas que poderíamos chamar de livros que contêm os saberes objetivados para a docência. Diz ele:

\footnotetext{
${ }^{9}$ O baiano Abílio César Borges, em 1871, instalou o seu Colégio Abílio no Rio de Janeiro e, dez anos mais tarde, ganhou do imperador D. Pedro II o título de Barão de Macaúbas. Abílio Borges foi autor do que Valente (2013) considera um best-seller. Desenho linear ou elementos de Geometria prática popular, de 1878. O livro de Abílio Borges tem enorme sucesso sendo publicado até 1960.
} 
As obras grandes de pedagogia, como de todas as sciencias, são para as estantes, de onde não sahem sinão para consultas: são obras para litteratos. Os resumos, porém, os compendios, como o que em bôa hora fez V. S., são os que podem e devem ser constantemente manuseados pelos moços aspirantes ao magisterio, pelos proprios mestres e até pelo povo (PONTES, 1881, p. III, Prefácio).

Em meio a elogios, Borges apontou um elemento que considerou faltar no Compêndio: o ensino de música. Porém, já na terceira edição da obra, o autor, em seu Prólogo, justificou-se e, ao fazer isso, mostrou ao leitor que a obra estava diretamente ligada ao programa de ensino do professado na Escola Normal. E, música não sendo parte dele, não teria como integrá-la ao Compêndio. Ponte, também, se desculpou por ter escrito obra algo elementar, mesmo tratando de pedagogia, considerada por ele "uma ciência muito complexa". Porém, disse ele: "(...) como entrar em grandes desenvolvimentos philosophicos em um compendio destinado a alumnos de quem se exigiram como condições litterárias para a matricula, apenas rudimentos de instrucção primaria?" (PONTES, 1881, p. VI, Prefácio).

Ainda no Prólogo, Pontes chamou a atenção de que o seu manual, ao contrário do compêndio adotado anteriormente ${ }^{10}$ na Escola Normal da Província do Rio de Janeiro, atendia ao Programa de Ensino de 1869. Apesar da análise do programa não ter sido realizada neste texto, no período de 1817 a 1888, o contexto sóciocultural brasileiro passava por transformações significativas', conforme Martins (2009). De acordo com o autor, isto se devia 'à disseminação de ideias liberais e republicanas; à eclosão de vários movimentos abolicionistas e à discussão, nas academias de ideias evolucionistas e positivistas' (MARTINS, 2009, p.178). O autor afirmou que isto propiciou a expansão da escola pública elementar e consequentemente das escolas normais para formar o professor e que foi partir de 1870 que a escola normal passou a ser considerada como uma instituição legítima para preparar o professor para seu ofício. Villela (2002), também, precisou em sua tese que, além da institucionalização desse lugar próprio destinado a esta formação, entre 1860 e 1880 a Província do Rio de Janeiro assistiu a uma mudança de um modelo de formação antes baseado na imitação de práticas pedagógicas para um modelo profissional. Mais especificamente, no período entre 1868 e 1876, em que a Escola Normal de Niterói foi dirigida por José Carlos de Alambary Luz, uma nova fase se iniciou "caracterizada pela modernização de conteúdos, métodos materiais pedagógicos" (VILLELA, 2002, p.46). Assim, para além de apropriações de obras estrangeiras, nota-se que o autor tendo o programa de ensino por referência, preocupava-se com a elaboração de um guia para o trabalho docente, uma referência a ser levada em conta na formação de professores, uma sistematização de como, a partir do programa de ensino, devia-se entender os saberes profissionais da docência, ainda que essa terminologia não tenha sido utilizada.

O compêndio de Antônio Pontes foi organizado em três partes. Uma primeira parte com noções preliminares, que incluía o primeiro capítulo sobre a definição, importância e

\footnotetext{
${ }^{10}$ O autor se referia ao manual "Curso Prático de Pedagogia" de Mr. Jean Baptiste Daligault (1874), traduzido por Joaquim Pires Machado Portella, obra analisada por Trevisan (2011). Esta obra compõe a coleção de livros raros, da Biblioteca Bourroul, integrante dos acervos da FEUSP, e está disponível para consulta local. A primeira publicação em francês se deu em 1851 (TREVISAN, 2011, p. 87).
} 
fim da educação, em que apresentava a Pedagogia, trazendo a divisão e a diferença entre educar e instruir. No segundo capítulo apresentou as principais virtudes do bom professor representadas pela: gravidade, discrição, prudência, bondade, paciência, firmeza, modéstia, polidez, amor do retiro e estudo, exatidão e zelo, piedade e bons costumes e por último a vigilância (PONTES, 1881, p. 8). A segunda parte do compêndio distribuiu-se com um primeiro capítulo à educação, tratando da higiene, da educação física (ginástica), principais lições a serem ensinadas e a educação dos órgãos dos sentidos. O segundo capítulo dedicado à educação moral, ensinando sobre a vontade, sensibilidade e tendências (intelectual, social e religiosa), e o capítulo terceiro reservado à educação intelectual, orientando o leitor sobre os processos de inteligência como atenção, percepção, comparação, juízo, raciocínio (dedução e indução) e memória.

Somente na terceira parte da obra, tem-se o tratamento da instrução. Em seu capítulo I, apresentou os princípios relativos à educação (princípios relativos ao professor, aos discípulos e aos objetos de ensino). O capítulo II é destinado à explicação dos métodos de ensino (individual, simultâneo, mútuo e misto), intitulado, Metodologia Geral. Do capítulo III ao capítulo VIII ${ }^{11}$ o autor tratou dos métodos de matérias escolares, como é o caso do "método da Aritmética" e ensinos de determinadas rubricas, como no caso do "Desenho Linear e Geometria Plana". Esta parte, inserida no que o Pontes denominou "Methodologia Especial" foi referenciada pelo autor que afirmava ter sido inspirada no "Cours Theorique $e$ Pratique de Pédagogie" do autor belga, Thomas Braun, publicado em Bruxelas. Trata-se de exemplo de apropriação de textos estrangeiros para uso no Brasil, algo muito comum no final do século XIX e início do século XX (TREVISAN, 2011).

Dos capítulos XIX e $X, 0$ autor trouxe temas que abordassem, respectivamente, a organização geral da escola (classificação dos alunos, organização material e divisão do tempo), e a disciplina escolar, apresentando os princípios gerais de disciplina, punições e recompensas. Os deveres do professor foi tema do último capítulo do manual.

À vista do Compêndio de Silva Pontes, repõe-se a questão: Que matemática para ensinar na Escola Normal de São Paulo está objetivada no "Compêndio de Pedagogia: para uso dos alumnos da Escola Normal da Província do Rio de Janeiro (1881)", de Antônio Marciano da Silva Pontes?

As análises deste artigo se concentrarão, especialmente, nos capítulos IV, V e VII os quais dão maior visibilidade aos elementos do saber profissional específicos à matemática (aritmética, desenho linear e geometria plana).

\section{O Compêndio de Pedagogia de Silva Pontes e a matemática para ensinar}

Silva Pontes (1881) iniciou as explicações sobre o "methodo" em seu manual escrevendo que "Para ser bom professor, não é bastante conhecer as matérias do ensino, é preciso também saber ensinal-as [...]" (PONTES, 1881, p. 103).

\footnotetext{
${ }^{11}$ Neste capítulo III, de metodologia especial, é reservado à Leitura e ao Ensino de leitura. O capítulo IV, apresentou o Ensino da escrita. O capítulo V, o Methodo da Arithmetica, Ensino Religioso, Ensino da Geographia. O capítulo VI foi reservado ao Ensino do desenho linear e o capítulo VII ao Methodo da Gramatica. O Ensino da geometria plana foi tema do capítulo VIII.
} 
No seu manual está presente a difusão de ensinos e métodos específicos para o professor ensinar no curso primário como: leitura e método de leitura, método de aritmética, ensino de religião, ensino de desenho linear, ensino de geometria, método de gramática etc.

Desde logo, chama-nos a atenção a designação dos capítulos. Para a Aritmética, temse o tratamento dado como "método"; para o Desenho Linear e para a Geometria plana, os escritos referem-se à discussão sobre o "ensino". Na leitura das páginas dedicadas a essas rubricas escolares é possível, comparativamente, compreender essas diferentes designações. No caso da Aritmética, aborda-se uma matéria escolar já consolidada, consagrada nos programas de ensino. Caberá apresentar uma proposta para o professor ensiná-la, não havendo necessidade de explicitar detalhadamente os seus conteúdos. Desse modo, o autor optou por discutir o método a seguir na Aritmética à vista de conteúdos já estandardizados desde longa data. Diferentemente para o caso do Desenho Linear e para a Geometria Plana, onde parece não haver consensos estabelecidos, caberá mencionar a importância dessas matérias de ensino e a ordem a seguir dos conteúdos a ensinar. Assim, o autor enfatizou os conteúdos que deveriam ser ensinados nessas rubricas.

Que elementos de uma matemática para ensinar estão explicitados, objetivados no tratamento dado às rubricas Aritmética, Desenho Linear e Geometria Plana, abordadas por Silva Pontes, em seu Compêndio de Pedagogia?

Iniciemos a análise pela Aritmética. $\bigcirc$ "methodo da Arithmetica" traz orientações aos professores para o ensino da mais "árida" matéria na escola primária, segundo Pontes (1881). De um modo geral, as orientações dadas aos professores referem-se ao combate de práticas pedagógicas que insistiam na memorização. O autor intentou convencer os professores que estava em voga um novo modo de ensino. Um ensino em conformidade com as propostas pestalozzianas que defendiam uma proposta de ensino baseada na intuição levando em conta a psicologia infantil e o contexto vivido pela criança. Nele, deviase afastar o trabalho com a memorização sem entendimento. A aritmética deveria ser ensinada a partir do cálculo verbal. E tal prática não deveria ser confundida com memorização, como saber de cor simplesmente.

Ensinar a criança pelo cálculo verbal e não pelo cálculo escrito infere que o professor deva conhecer tais tipos de cálculos, e, também, os princípios do método intuitivo. Desse modo, para o autor, a lição devia ser ensinada partindo de objetos conhecidos pela criança, levando-a a verbalizar a sua resposta a partir da compreensão de exemplos apresentados.

O autor chamou à atenção para que o professor não confundisse a prática do cálculo mental com memorização sem entendimento. Novamente, Pontes evocava os processos intuitivos:

Entretanto é mister não se enganar sobre a significação do calculo mental, como aqui empregamos. Com efeito trata-se de memoria, e de operações algum tanto mechanicamente executadas, como resultados de esforços e de habito. - Mas antes de repetidos e confiados á memória, taes calculos devem ter sido intuitivos, e por isso bem comprehendidos. Não será só por ter decorado na taboada, que a criança diz que tres, mais tres fazem seis, mas sim por se the ter mostrado por meio de objectos materiaes (PONTES, 1881, p. 158, grifos do autor).

O autor apresentou, também, métodos para ensinar numeração falada, tabuada e o sistema métrico. $\bigcirc$ ensino da numeração falada antecedia o ensino da numeração escrita. 
Novamente estava aí a preocupação de considerar que a criança não sabe ler, nem escrever. E, assim sendo, ela deveria verbalizar, expressar-se oralmente. Mas o professor poderia, segundo o autor, fazer a criança verbalizar a numeração de modo prazeroso, sem pensar que está a pronunciar a numeração falada. O professor, dessa maneira, era orientado a conhecer materiais que fizessem parte das brincadeiras das crianças, como alguns brinquedos e jogos, e que as fizessem "contar". Neste caso, o autor cita o dominó, bilboquet ou malha (PONTES, 1881, p.159, grifos do autor).

Ao citar os materiais de ensino vindos das brincadeiras infantis, o autor fazia uma ressalva: ensinar com estes dispositivos apenas nos recreios ou nas horas de descanso para que se mantenham a ordem e disciplina da aula. O trabalho ativo do professor, na aula, de outra parte, sem que usasse jogos, poderia ser substituído, com "o mesmo fim com suma vantagem os quadros de ensino por imagens e outros geralmente empregados no ensino intuitivo" (PONTES, 1881, p. 159). Essas anotações levam-nos a bem verificar as diferenças estabelecidas posteriormente entre "ensino ativo" e "escola ativa". O primeiro tendo em vista as ações realizadas pelo professor, um professor ativo; a segunda caracterização, posta para a Escola Nova, onde os processos e dinâmicas envolvidas na aula partem da criança e não do professor.

Vidal (2005) bem explicita as principais ideias de ambos os modelos, realçando as diferenças entre ensino ativo e escola ativa:

Apesar de surgirem como similares em muitos discursos do período, ensino ativo e escola ativa distinguiam-se na fala dos escolanovistas pela própria concepção de atividade. Se a primeira acepção concernia à maneira como o conteúdo deveria ser trazido ao aluno e supunha a atividade dos professores na realização de experiências e no oferecimento de imagens e objetos que concretizassem a aula; a segunda deslocava para os alunos a feitura das tarefas. Era pela ação dos métodos de projeto e centros de interesse que as crianças deveriam solucionar problemas e construir experimentos, ainda que sempre orientadas pelos docentes (VIDAL, 2005, p. 11).

No caso da tabuada da adição, segundo exemplo dado pelo autor do manual, a sua memorização deveria se dar fazendo com que a criança praticasse operações de adição e subtração com objetos que Ihe fossem comuns. De novo, o professor devia saber ensinar com uso de objetos que as crianças conhecessem. Somente depois que compreendessem as operações com objetos do seu dia-a-dia, a tabuada deveria ser ensinada, devendo ser seguida de exercícios e problemas considerados fáceis.

Com relação ao sistema métrico, as orientações do autor eram para que o professor apresentasse, primeiramente, objetos às crianças, por exemplo: o litro, como um cubo, ou seja, um decímetro cúbico, sem, no entanto, explicar o que viria a ser cubo, ou qual a origem da palavra metro. Percebe-se que sempre o ensino deveria partir de objetos do mundo da criança, que Ihe fossem comuns, para ensinar tabuada, operações, numeração falada.

Pontes, também, chamou à atenção para que o professor não se sentisse fatigado com erros que os alunos pudessem cometer em operações simples, pois isto era bem específico de cada um, era preciso compreensão por parte do professor. Segundo o autor, a operação de adição devia ser ensinada levando em conta números simples, depois números com dois algarismos e assim por diante. Esta ordem devia ser obedecida, também, para o ensino de 
somas de frações, por exemplo. O professor era orientado, ainda, a repassar, a recapitular, sempre que necessário, uma lição ensinada, dada a incompreensão de alguma delas por parte do aluno. Pontes observou que de nada adiantava ficar discutindo a marcha de ensino, uma vez que, esta geralmente era imposta pelo manual indicado nos programas, especialmente em se tratando de escolas públicas. Tal observação mostra-nos, a partir de um manual de pedagogia, o quanto importante, também, deve ser a análise de obras específicas, obras que abordem a matemática. Elas ditarão a marcha do ensino, isto é, a programação, a sequência dos conteúdos a serem abordados.

Com relação ao uso de materiais concretos no ensino, Pontes trouxe orientação do uso de contadores mecânicos, um meio para ensinar cálculo de operações, que levava o aluno à "visualização" da operação e compreensão desta. No entanto, o autor advertiu que o uso de materiais, levava à dependência da criança destes meios, atrapalhando o cálculo de operações de outros modos (verbal, mental, por exemplo).

Para finalizar suas orientações referente ao "método da aritmética", Pontes afirmou que a depender do grau de adiantamento do aluno e de seu desenvolvimento intelectual, bastaria dividir a escola em quatro turmas, a primeira levaria em conta o ensino da intuição e prática verbal, a segunda a prática escrita e as tabuadas, a terceira o que já foi ensinado com os princípios teóricos e com exercícios com aplicações concretas e, em quarto lugar, as aplicações abstratas com as "teorias elevadas" (PONTES, 1881, p.163). Estas observações finais sobre a aritmética evidenciam, mesmo antes da emergência dos grupos escolares, um modo de organizar as classes, tendo em vista a graduação do ensino. Tal graduação, notese, tem por referência a matéria a ensinar e a sua concepção de ensino. Para a aritmética, num primeiro momento a intuição, tratada como prática verbal; num segundo, o início de sistematização pela escrita das formas intuitivas; num terceiro, a incorporação de saberes já sistematizados - "os princípios teóricos"; e o momento final, com o trato pedagógico afastado das aplicações concretas, tendo em conta as "teorias elevadas".

O tratamento do Desenho Linear e da Geometria Plana, como se mencionou anteriormente, é realizado nos capítulos VI e VIII, respectivamente. Para o Desenho Linear o autor ocupou-se em sumariar algo que já estava posto desde há muito tempo na cultura escolar do ensino primário: o desenho como matéria útil para o trabalho (LEME DA SILVA; VALENTE, 2014). A despeito de considerar que a prática do desenho linear possibilitaria o "desenvolvimento da inteligência", o que o autor reforçou é que:

O desenho linear muito principalmente merecia ser declarado como parte integrante do ensino primario, pois que as escolas são frequentadas, pela maior parte, por mininos pobres, e entre elles se acham muitos futuros artistas, a quem tal ramo de ensino um dia seria da maior utilidade, e tendo como todos os exercícios graphicos a vantagem de agradar ás crianças, é para estas uma util occupação desde os primeiros tempos na escola (PONTES, 1881, p. 175).

E, como se disse anteriormente, o autor ocupou-se em discriminar os conteúdos de ensino dessa matéria escolar orientando o professor a começar

(...) pela linha recta, e suas applicações: linhas horizontaes, verticaes, obliquas; linhas de uma extensão dada; linhas a dividir; linhas perpendiculares; angulos de diversas especies; angulos a dividir; triangulos de diversas especies; quadrilateros, polygonos etc. (...) Seguem-se depois dos exercicios sobre linhas curvas: circumferencia, arcos diversos, cordas, 
raios, diametros, tangentes, secantes etc., diversas combinações de circunferências; ellipses etc. (PONTES, 1881, p. 176-177).

A proposta do autor seguiu, como se disse, o que estava presente desde há muito tempo, isto é, desde a criação das escolas de primeiras letras no Brasil: o Desenho Linear constituía matéria escolar que não devia lançar mão de instrumentos, pelo menos durante grande parte de seu ensino, ficando para o final do curso tal expediente:

\begin{abstract}
À proporção que se fór adiantando, devem ir sendo mais difficeis os trabalhos: vem os planos, secções, perfis etc.; já as figuras desenhadas se suppõem vistas por muitas faces successivas, e de então em diante, vão se empregando modelos em relêvo ou objectos naturaes, e por meio de medidas exactas referidas a uma escalla. Então são empregados os instrumentos próprios do desenho, com os quaes serão repetidas as principaes construcções geometricas, a fim de que o alumno aprenda a servir-se delles (PONTES, 1881, p. 178).
\end{abstract}

Pontes tratou o Desenho Linear em seu livro defendendo a presença dessa rubrica escolar no curso primário em razão, sobretudo, de sua utilidade durante o curso e após a formação do aluno nesse primeiro nível de ensino. Explicitou os conteúdos a serem ensinados e o seu encadeamento.

Outra rubrica do ensino primário tratada no livro de Pontes foi a Geometria Plana. Como se disse, ela estava colocada pouco depois do desenho linear, no Capítulo VIII. O autor discorreu sobre o ensino de Geometria Plana a partir do "Regimento Interno das escolas primárias", expedido pela Diretoria de Instrução em 5 de abril de 1873. Tal como procedeu para o Desenho Linear, Pontes descreveu os conteúdos a serem tratados segundo tal documento:

"Linha recta, angulos retos. Propriedade das parallelas. Soma dos angulos de um triângulo, de um quadrilatero, de um polygono qualquer. Principaes casos de egualdade dos triangulos. Superficie do rectangulo dividido em quadrados eguaes. Superficie de um paralelogramo qualquer. Superficie do triangulo, do trapezio, de um polygono qualquer dividido em triangulos".

"Círculo, arco, cordas, diametros, tangentes e secantes. Angulos centraes, angulos inscriptos e circumscriptos. Medição da circumferência, e da superfície do círculo" (PONTES, 1881, p. 185-186).

Também para esta rubrica, nesse regulamento citado pelo autor, caberia o caráter utilitário a presidir o ensino: "o professor antes de começar a explicação de teoremas citará numerosos exemplos tirados da indústria ou das artes, e a cada proposição ajuntará as aplicações mais úteis, a fim de fazer compreender a verdade que quiser demonstrar" (PONTES, 1881, p. 186).

Posteriormente a essa explanação do autor, vinda de sua leitura do Regimento das escolas primárias, Pontes mencionou um novo documento, que substituiria essas diretivas anteriores. Em tom lamentoso, ao que tudo indica, apontou que o novo Regimento interno foi econômico e "limitou-se ao seguinte: art. 39, Parágrafo $4^{0}$.: Este estudo será prático e intuitivo dos elementos indispensáveis ao ensino do desenho; avaliação de superficies; conhecimento das fórmas geométricas" (PONTES, 1881, p. 186). 
Nessa menção explicita-se mais claramente o papel da geometria no ensino primário: deveria a geometria, em boa medida, servir ao desenho. Reforçava-se, para ambas as matérias, assim, a sua finalidade prática, garantida pelo modo intuitivo de serem ensinadas.

\section{Considerações Finais}

A análise da obra de Silva Pontes ateve-se, em específico, aos capítulos do livro que trataram da matemática (Aritmética, Desenho Linear e Geometria Plana). De outra parte, houve necessidade de melhor compreender o contexto da produção do livro, da posição ocupada por seu autor no âmbito educacional e, sobretudo, verificar que o texto foi elaborado de modo articulado aos programas de ensino vigentes, que norteavam a formação de professores. Não coube pensar o Compêndio de Pedagogia de Silva Pontes como obra de referência do campo educacional. Para além disso, de avaliar o seu trabalho como obra de cultura erudita, de pensador da educação, melhor direção da análise deunos o próprio Abílio Borges ao ponderar que "as obras grandes de pedagogia, como de todas as sciencias, são para as estantes, de onde não sahem sinão para consultas: são obras para litteratos" (PONTES, 1881, p. III, Prefácio). De outra parte, os compêndios, como o que elaborou Silva Pontes, "são os que podem e devem ser constantemente manuseados pelos moços aspirantes ao magistério, pelos próprios mestres e até pelo povo" (PONTES, 1881, p. III, Prefácio). Silva Pontes, em concordância com Borges, justificou-se: "(...) como entrar em grandes desenvolvimentos philosophicos em um compendio destinado a alumnos de quem se exigiram como condições litterárias para a matrícula, apenas rudimentos de instrucção primária?" (PONTES, 1881, p. II, Prólogo).

Retomemos a interrogação inicial: Que elementos de uma matemática para ensinar estão explicitados, objetivados no tratamento dado às rubricas de Aritmética, Desenho Linear e Geometria Plana, abordadas por Silva Pontes, em seu Compêndio de Pedagogia?

No que diz respeito ao trato com a Aritmética, os aspirantes ao magistério deveriam ter em conta que o início do trabalho pedagógico apontava para a necessidade de posse de um saber importante: o ensino do cálculo oral, o cálculo de modo verbalizado. Tal processo estava distante da tradição colocada pela escola que fazia uso da memória. Este será um saber profissional novo, ensinar oralmente a calcular, sem que haja memorização. Afinal, a criança não sabia nem ler, nem escrever. Primeiramente os objetos deviam ser apresentados às crianças, considerados como dispositivos a serviço da intuição. Sendo assim, era necessário que o professor soubesse ensinar pelo método intuitivo.

Um outro saber profissional novo refere-se ao tratamento a ser dado inicialmente às operações aritméticas. O professor precisava saber como ultrapassar a tradicional memorização da tabuada. Para tal, profissionalmente, tinha que saber como ensinar o cálculo mental. Para ensinar o cálculo mental, o professor já teria realizado com os alunos os cálculos intuitivos por meio de objetos empíricos. Ou seja, primeiramente se deveriam ensinar as operações com o uso de objetos que fizessem parte do universo da criança, depois repeti-las, e com esforço e hábito, os resultados desse trabalho seriam confiados à memória. As operações seriam mais facilmente memorizadas se o ensino se desse por processos intuitivos. A memória viria pelo entendimento das operações com objetos concretos e não, pelo fato do aluno ter sido levado a decorar a tabuada. Como se vê, um saber que o professor deveria possuir muito distinto do que já estava assentado há muito tempo nas práticas dos professores. 
O "método da aritmética" de Silva Pontes reúne uma aritmética para ensinar que busca uma ruptura com a tradição. Não basta ao aspirante a professor realizar o que a sua vida de aluno do curso primário provavelmente consagrou: o uso da palmatória como instrumento profissional do mestre, acionando-a todas as vezes que o aluno errasse os valores que deveria decorar vindos das tabuadas. A nova aritmética para ensinar, bem entendido, não prescinde de todos os conteúdos de ensino consagrados. Está articulada a uma aritmética a ensinar, posta nos manuais de aritmética dos tempos de Silva Pontes. Como bem notou o autor, não há que se discutir muito a marcha do ensino, pois ela está posta nos livros didáticos adotados pelos programas de ensino. As rubricas de Desenho Linear e de Geometria Plana mostram-se algo diferente no Compêndio de Silva Pontes relativamente à Aritmética. Não constituem elas rubricas estabilizadas na formação de professores. Nem de longe possuem consensos de que deveriam integrar essa formação e participar do ensino nos primeiros anos escolares. Desde a criação das escolas de primeiras letras, após a Independência, são temas de debates (VALENTE, 1999). Assim sendo, de modo diferente da Aritmética, as ponderações colocadas por Silva Pontes em seu Compêndio, em boa medida, ligam-se à defesa da presença dessas rubricas na formação de professores, tendo em vista - caráter prático-utilitário que a elas poderá ser atribuído. A obra não propõe um contraponto a uma cultura estabelecida de ensino dessas rubricas no curso primário, não aponta para uma mudança no saber profissional do professor no tratamento delas. Reafirma a necessidade de que elas sejam tratadas com vistas à sua utilidade na vida do aluno. Para tal, há que considerar uma sequência de conteúdos a ensinar, direcionados à utilidade da vida cotidiana. As rubricas de Desenho e Geometria Plana têm presença garantida nos programas do ensino secundário. Esse fato parece ser o contraponto do autor quando elabora seu discurso aos futuros professores do curso primário: o tratamento delas deverá afastar-se do livresco, do abstrato, longe ensinar teoremas por si só, deverá articular essa necessidade aos exemplos tirados das artes, da indústria. São diretivas sem método, sem a objetivação de um saber profissional, sem que sejam melhor explicitados saberes para ensinar essas rubricas. Tais rubricas ainda estavam sendo configuradas em saber profissional do professor que fosse ensinar matemática, contrariamente ao que acontecia na Aritmética, já consolidada há algum tempo. Isto mostra que os saberes profissionais é uma construção histórica, passando por mudanças e permanências ditadas por uma apropriação de vagas pedagógicas e pela transformação da sociedade. No caso do Desenho e da Geometria Plana, no período da publicação do manual de Pontes, ainda não se tinha certo consenso dos saberes específicos para ensiná-las, por isso não pode ser caracterizado, em conformidade ao aporte teórico-metodológico escolhido, um saber profissional objetivado.

Por fim, é possível dizer que o Compêndio de Silva Pontes se revelou como documento importantíssimo que sistematizou e objetivou um saber profissional de seu tempo. Um guia "para moços aspirantes ao magistério". Para tornar-se professor a um tempo em que era bastante ter já cursado o ensino primário. Imerso num contexto internacional da vaga intuitiva, o Compêndio organizou uma matemática para ensinar. Sem deixar de mostrá-la articulada a uma matemática a ensinar. E tal conclusão mostrou-se ainda mais verdadeira para a Aritmética, na indicação de uma aritmética para ensinar. 


\section{Referências}

BARBIER, J.-M. Savoirs théoriques et savoirs d'action. Paris: PUF, 2014 [1996].

DALIGAULT, J. B. Curso practico de pedagogia: destinado aos alunos-mestres das escolas normaes primarias e aos instituidores em exercicio. Tradução de Joaquim Pires Machado Portella. 2. ed. melhorada pelo traductor, e acompanha da traducção de uma lição de Mr. Dumouchel sobre os métodos. Rio de Janeiro: A. A. da Cruz Coutinho, 1874. 206 p.

GUIMARÃES, M. A. A aritmética escolar e o método intuitivo: um novo saber para o curso primário (1870 - 1920). 2017. 213f. Tese (Doutorado em Ciências). Universidade Federal de São Paulo, Guarulhos, 2017.

HOFSTETTER, R.; SCHNEUWLY, B. Hofstetter, R; Schneuwly, B. Savoirs en (trans) formation: Au coeur des professions de l'enseignement et de la formation. In: HOFSTETTER, Rita et al. (Éds). Savoirs en (trans) formation. Raisons éducatives. Bruxelles: De Boeck Université., 2009, p. 7-40.

LEME DA SILVA, M.C.; VALENTE, W. R. (orgs.). A geometria nos primeiros anos escolares história e perspectivas atuais. São Paulo: Papirus Editora, 2014.

OLIVEIRA, M. A.. A aritmética escolar e o método intuitivo: um novo saber para o curso primário (1870 - 1920). 2017. 280f. Tese (Doutorado em Ciências). Universidade Federal de São Paulo, Guarulhos, 2017.

OLIVEIRA, M. C.; FISCHER, M. C. B.; RIOS, D. F.; BÚRIGO, E. Z.; MACIEL, V.B.. Os manuais pedagógicos e a formação de professores que ensinavam matemática no curso primário. In: MENDES, Iran Abreu e VALENTE, Wagner Rodrigues, A Matemática dos Manuais Escolares, Curso primário, 1890 - 1970. São Paulo: Livraria da Física Editora, 2017.

PINHEIRO, N. V. L.. A aritmética sob medida a matemática em tempos da pedagogia científica. ANO. 245 f. Tese (Doutorado em Ciências). Universidade Federal de São Paulo, Guarulhos, 2017.

PONTES, A. M. da S. Compendio de pedagogia: para uso dos alumnos da escola normal da provincia do Rio de Janeiro. Rio de Janeiro: Typ. da Reforma, 1881. 238 p.

SILVA, M. R. I. S. A matemática para a formação do professor do curso primário: Aritmética como um saber profissional (1920-1960). 2017. 177f. Tese (Doutorado em Ciências). Universidade Federal de São Paulo, Guarulhos, 2017.

ROULLET, M. Les manuels de pédagogie - 1880-1920. Paris: PUF, 2001.

TREVISAN, T. A. História da disciplina Pedagogia nas escolas normais do Estado de São Paulo (1874-1959). 2011. 220f. Tese (Doutorado em Educação) - Faculdade de Filosofia e Ciências, Universidade Estadual Paulista, Marília, 2011. Disponível em: https://www.marilia.unesp.br/Home/PosGraduacao/Educacao/Dissertacoes/trevisan_ta_do_ mar.pdf. Acesso em: 10 de junho de 2018.

UBRICH, G. La méthode intuitive de Ferdinand Buisson: histoire d'une méthode pédagogique oubliée. 2011. Thèse de doctorat en Sciences de l'Education. Université de Rouen. Disponível em: http://shs-app.univ-rouen.fr/civiic/memoires_theses/textes/These-GUBRICH.pdf. Acesso em: 13 de junho de 2018. 
VALENTE, W. R. Que geometria ensinar? Uma breve história da redefinição do conhecimento elementar matemático para crianças. Pro-Posições [online]. 2013, vol.24, n.1 [cited 2018-06-01], pp.159-178. Disponível em: http://dx.doi.org/10.1590/S010373072013000100011. Acesso em: 03 de julho de 2018.

VALENTE, W. R. Uma história da matemática escolar no Brasil, 1730-1930. São Paulo: Annablume, 1999.

VALENTE, W. R. A matemática na formação do professor do ensino primário: São Paulo, 1875-1930. São Paulo: Annablume, Fapesp, 2011.

VALENTE, W. R. El saber profesional del profesor que enseña matemática: el futuro del passado. Revista Paradigma. 2018, vol. XXXIX, n. 39 (extra), junio de 2018, pp. 190-201. Disponível em: http://revistas.upel.edu.ve/index.php/paradigma/article/view/6902. Acesso em 10 de julho de 2018.

VIDAL, D. G. Culturas escolares: estudo sobre prática de leitura e escrita na escola pública primária (Brasil e França, final do século XIX). Campinas, SP: Autores Associados, 2005.

VILLELA, H. Da palmatória à lanterna mágica: a Escola Normal da Província do Rio de Janeiro entre o artesanato e a formação profissional. 2002. 291f. Tese (Doutorado em Educação) - Faculdade de Educação, Universidade de São Paulo, São Paulo, São Paulo, 2002. pt. 1. 